\title{
Dysmenorrhea among University Health Science Students, Northern Ethiopia: Impact and Associated Factors
}

\author{
Teshager Aklilu Yesuf $(\mathbb{D}$, Nigist Assefa Eshete, and Eskinder Ayalew Sisay \\ Department of Pharmacy, College of Health Sciences, Mekelle University, P.O. Box 1871, Mekelle, Ethiopia \\ Correspondence should be addressed to Teshager Aklilu Yesuf; teshe27@gmail.com
}

Received 28 September 2017; Accepted 25 December 2017; Published 21 January 2018

Academic Editor: Robert Gaspar

Copyright (C) 2018 Teshager Aklilu Yesuf et al. This is an open access article distributed under the Creative Commons Attribution License, which permits unrestricted use, distribution, and reproduction in any medium, provided the original work is properly cited.

\begin{abstract}
Background. It is estimated that more than half of all women in adolescence age suffer from dysmenorrhea and it often interferes with their daily physical and emotional aspects. It is the leading cause of short-term school absenteeism and is associated with a negative impact on academic and daily activities. Objectives. To investigate impacts of dysmenorrhea, factors associated with it, and its self-management strategies used by health science students. Methods. A cross-sectional institution based study was conducted among 246 Mekelle University health science students selected by stratified random sampling technique. Data were collected using self-administered semistructured questionnaire. Data were analyzed using SPSS 16. Results. The prevalence of dysmenorrhea was $71.8 \%$. Participants who had long menstrual cycle interval, long menses flows, and positive family history and who were alcohol users were more likely to had dysmenorrhea. Participants reported that $28.6 \%$ feel depressed, $16.2 \%$ are absent from class, and $22.9 \%$ had poor personal relationship due to dysmenorrhea and $78.2 \%$ of them practiced self-medication. Conclusion. Dysmenorrhea is common among Mekelle University health science students and it is major problem representing the cause of feeling depressed, poor personal relationship, and class absenteeism. Majority of the study participants used self-medication to treat dysmenorrhea.
\end{abstract}

\section{Introduction}

The term dysmenorrhea refers to severe painful cramping sensation in the lower abdomen often accompanied by sweating, tachycardia, headache, nausea, vomiting, diarrhea, and tremulousness occurring just before or during the menses. It is a common gynecological problem among adolescent females which is severe enough to affect their functioning [1$3]$.

Since the pain results from uterine vasoconstriction and contractions mediated by prostaglandins, the most reliable and effective treatment of dysmenorrhea is to inhibit prostaglandin synthesis using nonsteroidal anti-inflammatory drugs (NSAIDs) [4]. If symptoms do not respond to NSAIDs for three menstrual periods, combined oral contraceptive pills for three menstrual cycles can be tried $[5,6]$.

Several studies have shown that prevalence of dysmenorrhea varies greatly depending on methods of data collection. According to a study done in Jordan, the prevalence of dysmenorrhea was $90.1 \%$ [7]. In China, dysmenorrhea occurred on $37 \%$ of the menstrual dates on average and was unrelated to irregularity of menstrual cycles [8]. The symptoms of primary dysmenorrhea begin a few hours before menstruation begins and may peak during the heaviest flow during menstruation [9]; the most common symptoms are stomach cramp (78.0\%), backache (58.9\%), and mood change (56.9\%) [10].

Younger age, low body mass index, smoking, early menarche, prolonged or aberrant menstrual flow, premenstrual somatic complaints, pelvic infections, psychological disturbance, genetic influence, and a history of sexual assault influence the prevalence and severity of dysmenorrhea $[3,11]$. A study conducted in Jordan indicated that underweight, having a low family income, living in a rural area, and family history of dysmenorrhea were associated with dysmenorrhea [9]. A study conducted in Vietnam showed mean age and age at menarche, educational status, and religion were associated with dysmenorrhea [12]. A study conducted in Turkey showed that dysmenorrhea was significantly higher in coffee consumers, females with menstrual bleeding duration greater 
than or equal to seven days, and those who had a family history of dysmenorrhea [13]. Prevalence of dysmenorrhea decreased with increase in age $[14,15]$. An experimental study conducted in Iran showed that regular physical activity significantly reduced dysmenorrhea [16].

Dysmenorrhea affects the physical, psychological, and social status of female adolescents. According to study conducted in India among female medical students who reported dysmenorrhea, $31.67 \%$ and $8.68 \%$ were frequently missing college and classes, respectively [17]. A study done in South India showed that ibuprofen was taken by $80.95 \%$ of students [2] while a study done in Taiwan and Ghana showed that paracetamol was the most effective strategies in relieving dysmenorrhea [15, 18]. According to Egyptian study, fresh ginger was effective in relieving menstrual pain [19].

The objective of this study was to determine the prevalence of dysmenorrhea and assess its impact and management strategies used among Mekelle University health science students.

\section{Methods and Participants}

2.1. Study Design. A cross-sectional study was conducted from April to May 2014 in Mekelle University, College of Health Sciences, Northern Ethiopia. There were a total of 535 health science female students (medicine, pharmacy, public health, nursing, and dentistry). Considering 95\% confidence interval, $5 \%$ margin of error, $10 \%$ contingency for nonresponse rate, and $50 \%$ expected prevalence of dysmenorrhea, a sample of 246 students was calculated using single proportion formula. A two-step stratified random sampling technique was used to select study participants: sampling from each department and then sampling from each academic year based on appropriate proportion of the respective field of study.

Pretested self-administered semistructured questionnaire which was prepared in English was used to collect data. Ethical clearance was obtained from the institutional review board of Mekelle University and consent was sought from each participant. Data were coded and entered using SPSS 16 (SPSS Inc., Chicago, USA) for analysis. Frequencies, means, and standard deviations were calculated where appropriate for each of the variables. Binary logistic regression was done to determine factors associated with dysmenorrhea and $p$ value less than 0.05 was considered statistically significant.

\section{Results}

3.1. Participants' Background Information. Out of a total of 246 participants recruited to the study, 4 were excluded because of failure to complete the questionnaire, resulting in a response rate of $98 \%$. The mean age of the study participants was $20.5 \pm 1.16$ years. Most participants were freshman accounting $74(30.6 \%)$ (Table 1$)$.

Majority of participants 173 (71.8\%) experienced dysmenorrhea. More than half of the students (54.4\%) reported having a family history of dysmenorrhea (Table 2).

Multivariate logistic regression analysis showed that field of study, alcohol use, family history of dysmenorrhea, and
TABLE 1: Demographic characteristics of participants.

\begin{tabular}{|c|c|c|}
\hline Variables & Frequency & Percent \\
\hline \multicolumn{3}{|l|}{ Department } \\
\hline Medicine & 95 & 39.3 \\
\hline Pharmacy & 24 & 9.9 \\
\hline Public health & 25 & 10.3 \\
\hline Nursing & 81 & 33.5 \\
\hline Dentistry & 17 & 7.0 \\
\hline \multicolumn{3}{|l|}{ Academic year } \\
\hline First year & 74 & 30.6 \\
\hline Second year & 56 & 23.1 \\
\hline Third year & 70 & 28.9 \\
\hline Fourth Year & 36 & 14.9 \\
\hline Fifth year & 6 & 2.5 \\
\hline \multicolumn{3}{|l|}{ Religion } \\
\hline Orthodox & 179 & 74.0 \\
\hline Muslim & 28 & 11.6 \\
\hline Protestant & 31 & 12.8 \\
\hline Other & 4 & 1.7 \\
\hline \multicolumn{3}{|l|}{ Marital status } \\
\hline Unmarried & 222 & 92.9 \\
\hline Married & 17 & 7.1 \\
\hline \multicolumn{3}{|l|}{ Mothers' educational level } \\
\hline Unable to read and write & 26 & 11.0 \\
\hline Able to read and write & 65 & 27.4 \\
\hline High school & 40 & 16.9 \\
\hline Diploma and above & 106 & 44.7 \\
\hline
\end{tabular}

TABLE 2: Menstrual characteristics of participants, 2014.

\begin{tabular}{lcc}
\hline Variable & Frequency & Percent \\
\hline Menstruation cycle & & \\
21 days or less & 37 & 15.4 \\
23 to 34 days & 188 & 78.3 \\
35 or greater days & 15 & 6.2 \\
Menstruation cycle regularity & & \\
$\quad$ Regular & 163 & 67.4 \\
Irregular & 79 & 32.6 \\
Menstruation bleeding duration & & \\
2-3 days & 54 & 22.4 \\
4-5 days & 155 & 64.3 \\
6-7 days & 32 & 13.3 \\
Experience of dysmenorrhea & & \\
Yes & 173 & 71.8 \\
No & 68 & 28.2 \\
Family history of dysmenorrhea & & \\
Yes & 129 & 54.4 \\
No & 108 & 45.6 \\
\hline
\end{tabular}

duration of menses flow as well as menstrual cycle interval were significantly associated with dysmenorrhea (Table 3 ).

Most participants have lower abdominal pain (67\%). The majority of participants who had dysmenorrhea experienced 
TABLE 3: Factors associated with dysmenorrhea, 2014.

\begin{tabular}{|c|c|c|}
\hline Variables & $\operatorname{AOR}(95.0 \% \mathrm{CI})$ & $p$ value \\
\hline Field of study & & $0.047^{*}$ \\
\hline Medicine & Reference & \\
\hline Pharmacy & $1.95(0.479,7.90)$ & 0.352 \\
\hline Public health & $1.86(0.55,6.30)$ & 0.321 \\
\hline Nursing & $0.52(0.19,1.38)$ & 0.188 \\
\hline Dentistry & $0.05(0.01,0.85)$ & 0.039 \\
\hline Alcohol use & & $0.016^{*}$ \\
\hline Yes & $0.06(0.01,0.59)$ & \\
\hline No & Reference & \\
\hline Menstrual cycle & & $0.030^{*}$ \\
\hline Less than or equal to 21 days & $5.62(1.01,31.37)$ & 0.049 \\
\hline 22-34 days & $1.36(0.31,5.99)$ & 0.685 \\
\hline Greater than or equal to 35 days & Reference & \\
\hline Duration of menses & & $0.033^{*}$ \\
\hline 2-3 days & $4.20(1.01,17.61)$ & 0.050 \\
\hline 4-5 days & $1.34(0.36,5.01)$ & 0.663 \\
\hline 6-7 days & Reference & \\
\hline Family history of dysmenorrhea & & $0.001^{*}$ \\
\hline Yes & $0.27(0.13,0.59)$ & \\
\hline No & Reference & \\
\hline Constant & 0.06 & 0.529 \\
\hline
\end{tabular}

* Statistically significant at $p$ value $<0.05$; AOR: adjusted odds ratio.

TABLE 4: Dysmenorrhea associated symptoms and sites of pain, 2014.

\begin{tabular}{lcc}
\hline Symptoms & Frequency & Percent \\
\hline Lower abdominal pain & 163 & 67.4 \\
Back pain & 126 & 52.0 \\
Thigh pain & 20 & 8.3 \\
Headache & 94 & 19.8 \\
Dizziness & 131 & 27.5 \\
Nausea, vomiting, and diarrhea & 50 & 10.5 \\
Decreased concentration & 87 & 18.3 \\
Loss of appetite & 114 & 23.9 \\
\hline
\end{tabular}

their symptoms at the onset of menstruation flow (36.4\%). Dizziness was the commonest associated symptom, reported by $27.5 \%$ respondents, and loss of appetite was the second commonest associated symptom reported by $23.9 \%$ respondents (Table 4).

Most participants, 225 (94.1\%), did not smoke cigarettes. There were 27 (11.2\%) participants who use alcohol. Majority of participants, 137 (56.8\%), in this study have habit of drinking coffee. Participants reported that $28.6 \%$ of them feel depressed, $16.2 \%$ were absent from class, and $22.9 \%$ had poor personal relationship because of dysmenorrhea (Table 5).

Ibuprofen was used by $48 \%$ of participants. The majorities of the study participants use bed rest (33.6\%) and drink more water or tea $(31.6 \%)$ as a homemade remedy for dysmenorrhea (Table 6).
TABLE 5: Impacts of menstrual pain, 2014.

\begin{tabular}{lcc}
\hline Impact of menstrual pain & Frequency & Percent \\
\hline Poor concentration at class & 62 & 11.0 \\
Absent from class & 91 & 16.2 \\
Poor personal relationship & 129 & 22.9 \\
Feel depressed & 161 & 28.6 \\
Limitation of sleeping & 36 & 6.5 \\
Limit your exercise & 83 & 14.8 \\
\hline
\end{tabular}

TABLE 6: Medications and home remedies used for managing dysmenorrhea, 2014.

\begin{tabular}{lcc}
\hline Management strategies & Frequency & Percent \\
\hline Ibuprofen & 137 & 48.0 \\
Paracetamol & 34 & 12 \\
Diclofenac & 72 & 25.3 \\
Oral contraceptive pills & 2 & 0.7 \\
Apply pad & 71 & 16 \\
Bed rest & 150 & 33.6 \\
Drink more water or tea & 141 & 31.6 \\
Massage the site of pain & 69 & 15.5 \\
Drink different fluids such as soft & 15 & 3.4 \\
drinks especially coca cola & 40 & 14 \\
None & &
\end{tabular}




\section{Discussion}

In this study, the prevalence of dysmenorrhea was $71.8 \%$. This is similar to what is previously reported by Ghanaian adolescent girls, 74.4\% [18]. But dysmenorrhea was diagnosed based solely on a girls' perception of pain, which is difficult to quantify and could be related to nonmenstrual events.

Previous studies showed that the prevalence of dysmenorrhea decreases with increasing age and it is significantly associated with early age of menarche $[3,10,11]$. But age at first menarche had no association in our study. Length of menstrual cycle $(p=0.03)$ and duration of menses $(p=$ 0.033 ) were found to be associated with dysmenorrhea. In China, increased menstrual flows (median 4 days and $p<$ 0.05 ) have been reported to be associated with an increase in the severity of dysmenorrhea [8].

Positive family history of dysmenorrhea $(p<0.01)$ was significantly associated with dysmenorrhea. A similar result was obtained from India [2]. The fact that family history was shown to be a risk factor for dysmenorrhea may be related to the risk for related conditions such as endometriosis and genetic factors [13]. Alcohol drinking was also associated with dysmenorrhea $(p=0.016)$. In this study, regular exercise was not associated with experience of dysmenorrhea. But an experimental study done in Turkey found that participating in physical activity decreased the length of menstruation pain and volume of bleeding [16]. Menstrual pain may result from increased contraction of uterine muscle which is innervated by the sympathetic nervous system. Stress is supposed to increase the sympathetic activity which may lead to the increase of menstrual pain by enhancing the intensity of uterine contraction. So, due to the fact that exercise reduces stress, the sympathetic activity may be decreased. Physical activity also leads to the release of endorphins which are produced by brain and may enhance the pain threshold [16].

Dysmenorrhea is a cause of recurrent short-term school absenteeism in adolescent girls and a cause of work absenteeism in women of reproductive age. An estimated 10-15\% of women experience monthly menstrual pain severe enough to prevent normal daily function at school, work, or home [18]. In this study, $28.6 \%$ of participants reported they feel depressed which could affect their concentration in class and $16.2 \%$ of them reported missing classes. Although dysmenorrhea is not a life-threatening condition on its own, monthly recurrence of severe symptoms represents a significant morbidity.

Primary dysmenorrhea is attributable to increased endometrial synthesis of prostaglandins during menstruation. About 2-4 days before the onset of menstruation, prostaglandins proceed into the uterine muscle and cause uterine contractions that help in the expulsion of the endometrium. NSAIDs are the best established initial therapy for dysmenorrhea as they have direct analgesic effect through inhibition of prostaglandin synthesis and they also decrease the volume of menstrual flow [2]. The practice of self-medication appears to be widespread in the adolescent population with dysmenorrhea. In this study, $78.2 \%$ of participants reported self-medication. This result is higher than findings from
Ghana (51.5\%) [18]. Only 5.8\% of the study participants had consulted a physician in our study.

NSAIDs are highly effective in treating dysmenorrhea when they are taken before the onset of menses and continued through day two [18]. But our finding indicated that $73.7 \%$ of participants reported taking these medications when pain starts indicating the need for professional consultation.

\section{Conclusion}

Dysmenorrhea is a major problem representing the leading cause of class absenteeism. Females with long menstrual bleeding duration and long menstrual cycle interval, positive family history of dysmenorrhea, and alcohol drinking habit are more likely to experience dysmenorrhea. It is very important to create awareness about the causes and treatment of dysmenorrhea via the education system and media. Health professional consultation must be promoted to help students who have dysmenorrhea.

\section{Conflicts of Interest}

The authors declared no potential conflicts of interest with respect to the research, authorship, and/or publication of this article.

\section{References}

[1] M. Poureslami and F. Osati-Ashtiani, "Assessing knowledge, attitudes, and behavior of adolescent girls in suburban districts of Tehran about dysmenorrhea and menstrual hygiene," Journal of International Women's Studies, vol. 3, no. 2, pp. 51-61, 2002.

[2] B. Kiran, T. Sandozi, L. Akila, A. Chakraborty, Meherban, and RJ. Rani, "Study of the prevalence, severity and treatment of dysmenorrhea in medical and nursing students," International Journal of Pharma and Bio Sciences, vol. 3, no. 1, pp. 161-170, 2012.

[3] E. M. Mohamed, "Epidemiology of dysmenorrhea among adolescent students," Life Science Journal, vol. 9, no. 1, pp. 348-353, 2012.

[4] R. N. Okoro, H. Malgwi, C. K. Ngong, and G. O. Okoro, "Dysmenorrhoea: ways of management among nigerian university students," Actual Gynecology and Obstetrics, vol. 4, pp. 106-113, 2012.

[5] C. Liong, "The association of primary dysmenorrhea with the perception of pain, work stress and lifestyles of nurses," Hong Kong Medical Journal, vol. 23, no. 5, pp. 267-272, 2010.

[6] A. K. Gupta, A. K. Jaiswal, and S. Kumar, "Assessment of university campus student's awareness and attitude towards analgesics (NSAIDS)," Journal of Pharmaceutical Sciences and Research, vol. 5, no. 2, pp. 612-618, 2014.

[7] T. L. Mukattash, L. Tahaineh, N. AlRawi, A. Jarab, H. Hammad, and K. Nuseir, "Behaviors and attitudes towards dysmenorrhea; a crosssectional survey of 2,000 jordanian university students," Jordan Medical Journal, vol. 47, no. 1, pp. 26-34, 2013.

[8] H. Zhou, Z. Yang, and S. Group, "Prevalence of dysmenorrhea in female students in a Chinese university: a prospective study," Health, vol. 2, no. 4, pp. 311-314, 2010.

[9] J. E. Memmott, The Effect of Music-Assisted Progressive Muscle Relaxation on the Self-Reported Symptoms of Women with 
Primary Dysmenorrhoea, The University of Kansas, 2009, http://dissertations.umi.com/ku:10242.

[10] K. Tangchai, V. Titapant, and D. Boriboonhirunsarn, "Dysmenorrhea in thai adolescents: prevalence, impact and knowledge of treatment," Journal of the Medical Association of Thailand, vol. 87, supplement 3, pp. S69-S73, 2004.

[11] F.-F. Chung, C.-C. C. Yao, and G.-H. Wan, "The associations between menstrual function and life style/working conditions among nurses in Taiwan," Journal of Occupational Health, vol. 47, no. 2, pp. 149-156, 2005.

[12] I. A. Jang, M. Y. Kim, S. R. Lee, K. A. Jeong, and H. W. Chung, "Factors related to dysmenorrhea among Vietnamese and Vietnamese marriage immigrant women in South Korea," Obstetrics \& Gynecology Science, vol. 56, no. 4, pp. 242-248, 2013.

[13] A. Unsal, U. Ayranci, M. Tozun, G. Arslan, and E. Calik, "Prevalence of dysmenorrhea and its effect on quality of life among a group of female university students," Upsala Journal of Medical Sciences, vol. 115, no. 2, pp. 138-145, 2010.

[14] A. Polat, H. Celik, and B. Gurates, "Prevalence of primary dysmenorrhea in young adult female university students," Archives of Gynecology and Obstetrics, vol. 279, pp. 527-532, 2009.

[15] H.-F. Cheng and Y.-H. Lin, "Selection and efficacy of selfmanagement strategies for dysmenorrhea in young Taiwanese women," Journal of Clinical Nursing, vol. 20, no. 7-8, pp. 10181025, 2011.

[16] N. Mahvash, A. Eidy, K. Mehdi, M. T. Zahra, M. Mani, and H. Shahla, "The effect of physical activity on primary dysmenorrhea of female university students," World Applied Sciences Journal, vol. 17, no. 10, pp. 1246-1252, 2012.

[17] S. Amita, "Prevalence and severity of dysmenorrhea among first and second year female medical students," Indian Journal of Physiology and Pharmacology, vol. 52, no. 4, pp. 389-397, 2008.

[18] S. Gumanga and A. Kwame, "Prevalence and severity of dysmenorrhea among some adolescent girls in a secondary school in Accra, Ghana," Postgraduate medical journal of Ghana, vol. 1, no. 1, 2012.

[19] H. Awed, T. El-Saidy, and T. Amro, "The use of fresh Ginger herbs as a home remedy to relieve primary dysmenorrhea," Journal of Research in Nursing and Midwifery, vol. 2, no. 8, pp. 104-113, 2013. 


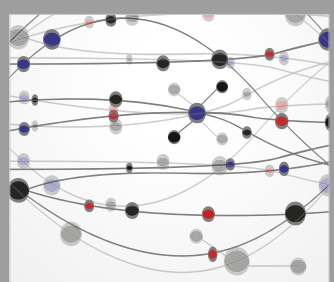

The Scientific World Journal
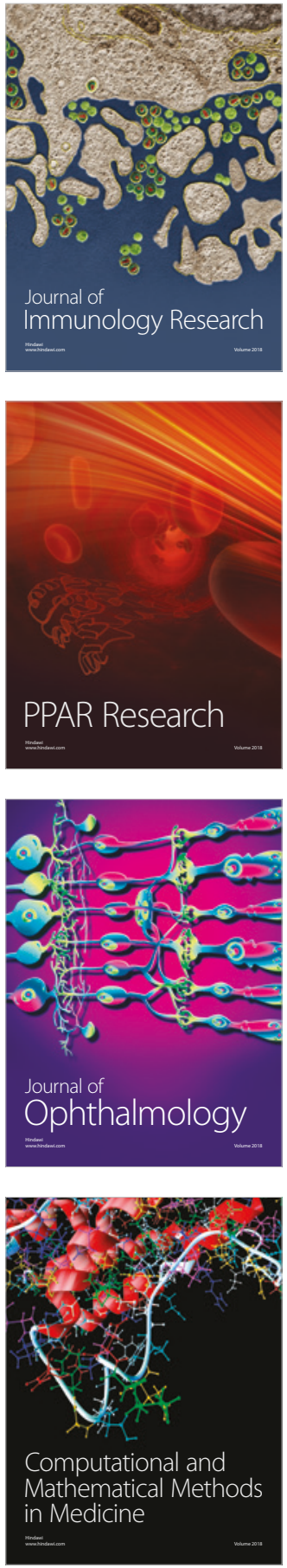

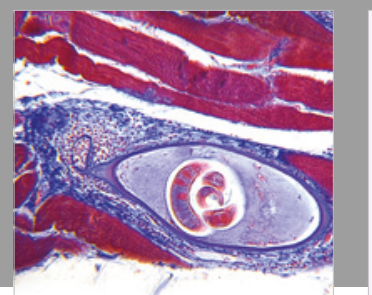

Gastroenterology Research and Practice

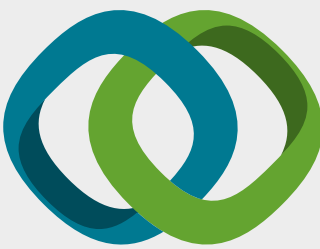

\section{Hindawi}

Submit your manuscripts at

www.hindawi.com
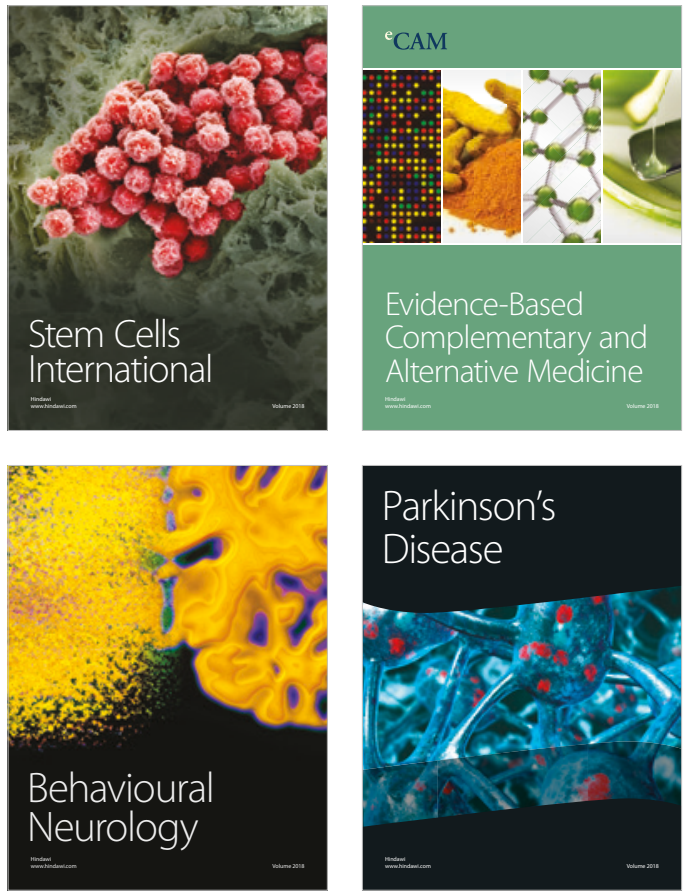

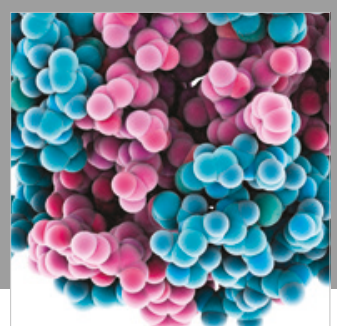

ournal of

Diabetes Research

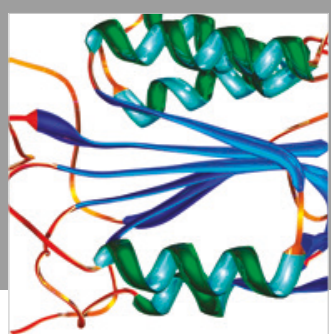

Disease Markers
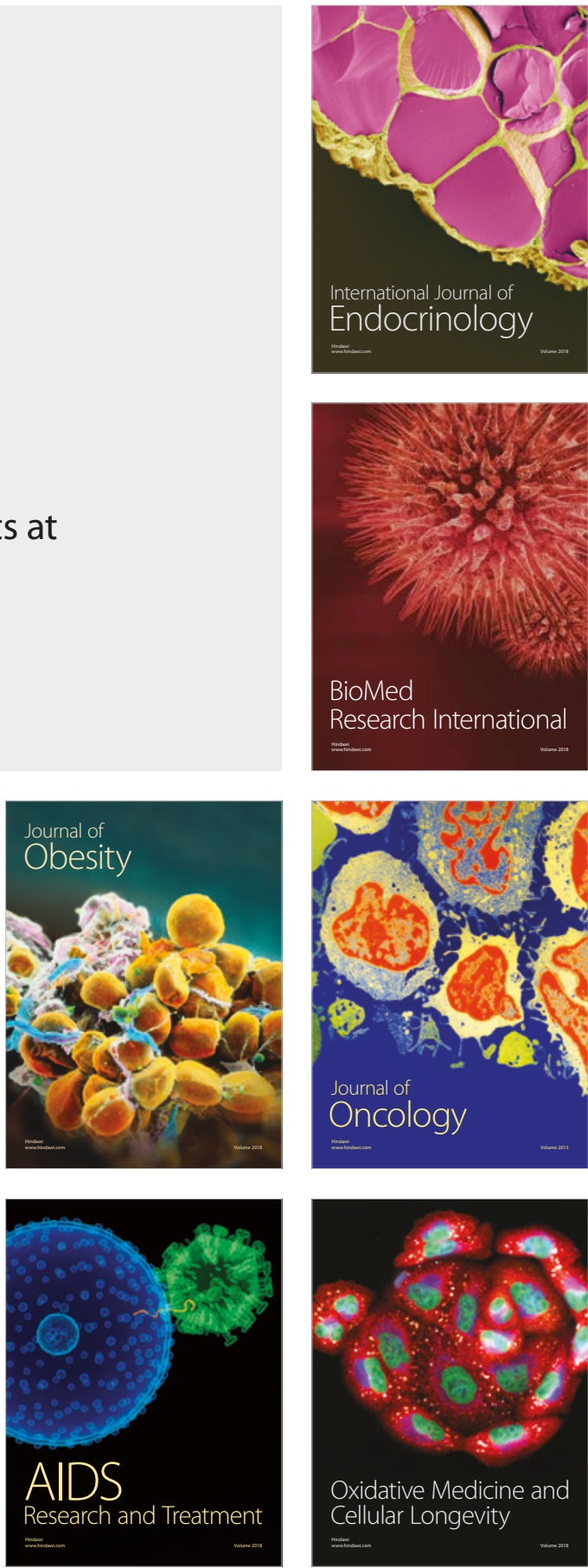